\title{
3D-printing Enabled Micro-assembly of Microfluidic Electroporation System for 3D Tissue Engineering
}

\author{
Qingfu Zhu ${ }^{\mathrm{a}}$, Megan Hamilton ${ }^{\mathrm{a}}$, Bryan Vasqueza ${ }^{\mathrm{a}}$, and Mei He $\mathrm{He}^{\mathrm{a}, \mathrm{b},{ }^{*}}$ \\ a. Department of Chemical and Petroleum Engineering, Bioengineering Program, University of \\ Kansas, Lawrence, Kansas, USA \\ b.Department of Chemistry, University of Kansas, Lawrence, Kansas, USA
}

\begin{abstract}
Electro-transfection is an essential workhorse tool for regulating cellular responses and engineering cellular materials in tissue engineering. However, most existing approaches, are only focused on cell suspensions in vitro, which fails to mimic in vivo tissue microenvironment regarding the 3D electric field distribution and mass transport in a biological matrix. However, building a 3D electro-transfection system that is compatible with 3D cell culture for mimicking in vivo tissue microenvironment is challenging, due to the substantial difficulties in control of 3D electric field distribution as well as the cellular growth. To address such challenges, we introduce a novel 3D micro-assembling strategy assisted by 3D printing, which enables the molding of 3D microstructures as the LEGO ${ }^{\circledR}$ parts from 3D-printed molds. The molded PDMS LEGO ${ }^{\circledR}$ bricks are then assembled into a 3D-cell culture chamber interconnected with vertical and horizontal perfusion microchannels as a 3D channel network. Such 3D perfusion microchannel network is unattainable by direct 3D printing or other microfabrication approaches, which can facilitate the high-efficient exchange of nutrition and waste for 3D cell growth. Four flat electrodes are mounted into the 3D culture chamber via a 3D-printed holder and controlled by a programmable power sequencer for multi-directional electric frequency scanning (3D $\mu$-electro-transfection). This multidirectional scanning not only can create transient pores all over the cell membrane, but also can generate local oscillation for enhancing mass transport and improving cell transfection efficiency. As a proof-of-concept, we electro-delivered pAcGFP1-C1 vector to 3D cultured HeLa cells within peptide hydrogel scaffolding. The expressed GFP level from transfected HeLa cells reflects the transfection efficiency. We found two key parameters including electric field strength and plasmid concentration playing more important roles than manipulating pulse duration and duty cycles. The results showed an effective transfection efficiency of $\sim 15 \%$ with $\sim 85 \%$ cell viability, which is a 3fold increase compared to the conventional benchtop $3 \mathrm{D}$ cell electro-transfection. This $3 \mathrm{D} \mu-$ electrotransfection system was further used for genetically editing 3D-cultured Hek-293 cells via direct delivery of CRISPR/Cas9 plasmid which showed successful transfection with GFP expressed in the cytoplasm as the reporter. The 3D-printing enabled micro-assembly allows facile
\end{abstract}

\footnotetext{
*Corresponding author meih@ku.edu.

Conflicts of interest

There are no conflicts to declare.

$\dagger$ Electronic Supplementary Information (ESI) is available for multi-directional frequency scanning video, as well as the monitoring of 3D cultured cells. See DOI: 10.1039/c91c00046a
} 
creation of novel 3D culture system for electro-transfection, which can be employed for versatile gene delivery and cellular engineering, as well as building in-vivo like tissue models for fundamentally studying cellular regulation mechanisms at the molecular level.

\section{Introduction}

Intracellular delivery of regulatory or therapeutic targets into the cell is crucial for pharmacology study as well as the tissue engineering and regenerative medicine. ${ }^{1-2}$ Among various delivery approaches such as using chemicals, ultrasound, and microneedle, electrotransfection has gained increasing popularity, due to its safe (chemical free) and effective transfection, and no restrictions on cell types. ${ }^{3-5}$

Electro-transfection is also termed as electroporation, which creates the transient permeabilization of the plasma membrane with temporary pores, due to high local transmembrane potential induced by an external electric field. However, existing electrotransfection systems, including microfluidic platforms and commercial benchtop systems, are only able to study monolayer cell suspensions in vitro, which is incapable of clinical translation within in vivo tissue microenvironment ${ }^{6-13}$. It has been well documented that cells growing in two-dimensional (2D) culture system significantly differ from living threedimensional (3D) tissues in terms of cell morphology, functions, cell-to-cell communications, and cell-to-matrix adhesions. ${ }^{14-15}$ Therefore, it is critical to use 3D cultured cells to represent in-vivo like tissue microenvironment. The knowledge regarding the 3D electric field distribution and mass transport in a tissue microenvironment is lacking. Electroporation performed on cell suspensions are very often but of limited use in 3D cells within a tissue microenvironment, because of the significant variations in terms of membrane interactions, surrounding medium, extracellular matrix, the orientation of cells to the electric fields and so on. ${ }^{16-17}$ Thus, the clinical in vivo gene delivery faces tremendous problems. ${ }^{3,18}$ Although the in vitro cellular spheroid model is often applied to study the electro-transfection in a 3D context, these studies only focus on single spheroid which fails to mimic the interactions between cells and the extracellular matrix. ${ }^{19-20}$

To date, the investigation of electroporation on 3D cultured cells and tissues has not been explored in the microfluidic platform yet. The benchtop method for electroporation study of $3 \mathrm{D}$ cells embedded in scaffolds showed very low transfection efficiency $(\sim 5 \%){ }^{21}$ The major challenge is the mass transport and mobility of delivered molecules in the cellular matrix are substantially restricted, and the migration becomes even more difficult when traveling into the cell spheroid. ${ }^{22}$ Benchtop chemical transfection can handle scaffold embedded spheroid 3D cells. However, the protocols are tedious and lengthy, and requires at least 24 hours for incubation. ${ }^{23-24}$ Herein, we introduce a novel 3D microfluidic electrotransfection system (3D $\mu$-electrotransfection) which provides facile, fast, and automated control for electrotransfection of 3D cultured cells. This 3D $\mu$-electrotransfection system is simply fabricated by the 3D printing-assisted 3D molding and micro-assembling strategy, which employs the LEGO ${ }^{\circledR}$ concept to assemble complicated 3D microchannel network as shown in Fig. 1a. Such 3D perfusion microchannel network is unattainable by direct 3D printing or other microfabrication approaches, while can facilitate the high-efficient exchange of 
nutrition and waste for 3D cell growth. The multi-directional electric field scanning was achieved by employing four flat electrodes mounted into the 3D culture chamber via a 3Dprinted holder and controlled by a programmable power sequencer (Fig. 1 e and f). This multi-directional scanning not only can create transient pores all over the cell membrane, but also can generate local oscillation for enhancing mass transport and improving cell transfection efficiency.

As a proof-of-concept, we electro-delivered the pAcGFP1-C1 Vector to 3D cultured HeLa cells in the peptide hydrogel scaffolding for expressing GFP. The critical parameters were optimized including electric field strength, plasmid concentration, pulse duration, and duty cycles. The $3 \mathrm{D} \mu$-electrotransfection system was further employed to genetically edit 3D cultured Hek-293 cells via delivery of CRISPR/Cas9 plasmid, which demonstrates the capability and holds the potential for future gene-editing based tissue repair, regenerative medicine, and gene therapy.

\section{Experimental}

3D printing and microfabrication of 3D $\mu$-electrotransfection.-3D structures were designed and drawn by SOLIDWORKS 2017. The resin mold containing microstructures were printed by a laptop-sized 3D printer (D3 ProJet 1200, 30- $\mu \mathrm{m}$ resolution) using VisiJet@FTX Clear resin (3D systems) for polydimethylsiloxane (PDMS) device production. The Clear resin consists of triethylene glycol diacrylate, sobornyl methacrylate, and 2-3\% photoinitiator phenylbis (2,4,6-trimethylbenzoyl)-phosphine oxide as described in the product information. The mold printing followed the reported protocols. ${ }^{25-26}$ Freshly printed molds were cleaned using isopropyl alcohol in sonication and followed with 30-min post cure under UV light. A 20-nm thick palladium or gold coating was deposited onto the surface of the 3D-printed mold using a sputter coater (DENTON, DESK II). Prior to molding, the coated molds were conditioned with the surfactant solution $(20 \%$ tween 20 in $80 \%$ isopropanol) for forming a dynamic micellar layer on the metal surface to facilitate the peel-off of polymer microstructures. PDMS was prepared using the standard 10:1 (base to curing agent) ratio. The PDMS mixture was degassed before pouring into the 3D-printed molds and then baked in $40{ }^{\circ} \mathrm{C}$ for 12 hours. The 3D printed molds are reusable after cleaning and conditioning. After the surface activation of molded PDMS pieces using a hand-held corona discharge treater (Electro-Technic Product, Chicago), the PDMS blocks were then assembled and bound as the 3D $\mu$-electrotransfection device (Fig. 1). The assembling was conducted on a flat stage under the microscope (here we use the PDMS port creator stage, CorSolutions Inc.) which can guide the alignment easily. The assembled 3D $\mu$ electrotransfection device was then bound to a glass slide to complete the fabrication.

3D cell culture and electro-transfection.-HeLa cells (ATCC) and Hek-293 cells (ATCC) were cultured and maintained according to the ATCC standard protocol with Eagle's Minimum Essential Medium (EMEM, Sigma-Aldrich), supplemented with 10\% $(\mathrm{v} / \mathrm{v})$ fetal bovine serum (FBS, Sigma-Aldrich), in a T-25 flask. The peptide hydrogel matrix (PepGel) was used as the scaffold with a peptide gel concentration of $0.2 \%$ for $3 \mathrm{D}$ cell culture. The 2D cells growing at a confluency of $80-90 \%$ were re-suspended by $0.25 \%$ trypsin/EDTA (Sigma-Aldrich) solution and centrifuged for 5 mins at $250 \mathrm{~g}$-force for 
seeding into peptide hydrogel. The seeding density for $3 \mathrm{D}$ cell culture was $\sim 2.5 \times 10^{5}$ cells $/ \mathrm{mL}$. The 3D cell culture was carried out following the protocol described in the literature. ${ }^{27}$ The medium exchange was performed from both the top of perfusion channels and center cell culture chamber. From the top opening, we used a sharp pipette tip or syringe to suck out $2 / 3$ of the old medium and inject in the same amount of fresh medium.

A 4.7 Kb plasmid pAcGFP1-C1 (Clontch, Mountain View) encoding green fluorescent protein (GFP) was amplified in the NEB® 5-alpha Competent E.coli (New England Biolabs, Ipswich) and isolated by QIAGEN Plasmid Maxi kit (QIAGEN GmbH). The plasmid purity was determined using Nanodrop 2000 spectrophotometer. A 9.2 Kb CRISPR /Cas9 vector pSpCas9(BB)-2A-GFP (PX458) (Addgene, MA) was amplified and purified following the same protocols as the preparation of GFP plasmid. The 2D standard electroporation protocols (Neon ${ }^{\circledR}$ transfection system) were used for validation of 3D $\mu$-electrotransfection system. The successfully transfected cells can express GFP as the reporter and be analyzed under flow cytometry (BD FACSAria IIIu, BD Biosciences) and confocal microscope (Olympus IX81/3I spinning disk confocal inverted microscope).

3D COMSOL simulation.-The AC/DC module was applied to simulate electric field distribution in 3D $\mu$-electrotransfection system using COMSOL Multiphysics software package (COMSOL Multiphysics 5.2). The equation governing electrostatics was numerically solved for the device to arrive at steady-state solutions. At steady state, the electric currents in a conductive media is given by the Ohm's law, which states

$$
\mathrm{J}=\sigma \mathrm{E}+\mathrm{J}_{e}
$$

Where $\sigma$ is the electrical conductivity, $\phi$ is the electric potential, $\mathbf{J}$ is the current density and $\mathbf{E}$ is the electric field. Electric field distribution was visualized using below expression,

$$
\mathbf{E}=\operatorname{sqrt}(\mathrm{es} . \mathbf{E x} * \mathrm{es} . \mathbf{E x}+\mathrm{es} . \mathbf{E} \mathbf{y} * \mathrm{es} . \mathbf{E} \mathbf{y}+\mathrm{es} . \mathbf{E z} * \mathrm{es} . \mathbf{E z})
$$

where es.Ex, es.Ey, and ex.Ez are the components of the electric field in the dimension of $\mathrm{x}$, $\mathrm{y}, \mathrm{z}$, respectively. The conductivity of electroporation buffer was set at $0.14 \mathrm{~S} / \mathrm{m} .{ }^{28}$ The relative permittivity of peptide hydrogel was set at 1 from the literature for the similar peptide hydrogel. ${ }^{29}$ We carried out electrostatic numerical simulations to predict the distribution of electric field strength across the entire cell culture chamber. The multidirectional electric frequency scanning was simulated and performed following the protocol as shown in Fig. 2b. To simulate nutrient medium exchange and diffusion in 3D $\mu$ electrotransfection system, the transport of diluted species in porous media model was studied in a time-dependent manner. Three different cases, i.e. medium diffusion from top medium to cell matrix, medium diffusion from side perfusion microchannel network to cell matrix, and medium from both top and side perfusion microchannel network to cell matrix were investigated for comparison.

3D multi-directional electro-transfection.-The voltage across 3D cell culture chamber in multi-directional scanning was programmed and delivered by HVS448 800 high 
voltage sequencer (LabSmith, CA, USA), which generated a square-wave electric pulse (see the Supplemental Video). Prior to applying the voltage, the cell medium (EMEM) was removed and $100 \mu \mathrm{L}$ low conductivity medium (Cytoporation ${ }^{\circledR}$ Medium T, BTX) was added on top as well as in the side perfusion channels. The electric potentials were applied to flat electrodes ( $\mathrm{Ag} / \mathrm{Pa}$ alloy, $3.5 \mathrm{~mm}$ width and $0.2 \mathrm{~mm}$ thick, Fisher). The electrodes were mounted by a customized holder, which was printed by a 3D printer (D3 ProJet 1200) as shown in Fig. 1e. For transfection, the GFP plasmid was prepared in the gel matrix with cells to achieve a final concentration between 60 to $140 \mu \mathrm{g} / \mathrm{mL}$. Cell culture was kept on ice during electroporation. Pulses at a frequency of $1 \mathrm{~Hz}$ were applied with a given electric field intensity. After electroporation, low conductivity medium in cell culture was replaced by EMEM medium (pre-conditioned in 5\% $\mathrm{CO}_{2}$ ). The transfected 3D cells were cultured for two days and assessed their GFP expression level by fluorescence microscopy and flow cytometry.

Investigation of cell membrane electro-permeabilization and propidium iodide delivery.-3D cells were seeded on chip according to the previously described 3D culture method. After 24 hours after cell seeding, the culture medium was replaced by low conductivity medium and $20 \mu \mathrm{L}$ of $10 \mu \mathrm{g} / \mathrm{mL}$ propidium iodide solution (PI, sigma-Aldrich, USA) was added on the top of the cell culture. After 30 min incubation, the electroporation was performed. To investigate the influence of multi-directional electric field on the delivery of PI, four parallel experiments were conducted in terms of different electric field directions i.e. single direction, two cross directions, three directions and four directions (Fig. 2 and Fig s1). The total pulse duration was $32 \mathrm{~ms}$ for each experiment. The transfected cell cultures were transferred from chip to a $1.5 \mathrm{~mL}$ centrifuge tube. Without removing the upper layer cell medium, the gel was mechanically disrupted thoroughly by pipetting up and down. The mixture was centrifuged at $600 \mathrm{~g}$ for $6 \mathrm{~min}$. To break colonies, $100 \mathrm{uL}$ accumax ${ }^{\mathrm{TM}}$ solution (Sigma-Aldrich, USA) was added and incubated for $5 \mathrm{~min}$ at $37^{\circ} \mathrm{C}$. The results have been evaluated by cyto-spinning the cells on glass slide followed with fluorescence microscopy analysis.

Flow cytometry analysis for assessing 3D electro-transfection efficiency and cell viability.-The ready $3 \mathrm{D}$ transfected cultures were transferred from chip to a $1.5 \mathrm{~mL}$ centrifuge tube according to the method described in the PepGel protocol. The colonies were separated by accumax ${ }^{\mathrm{TM}}$. To stain the dead cells, $5 \mu \mathrm{L}$ of $10 \mu \mathrm{g} / \mathrm{mL}$ PI was added and incubated in dark for $2 \mathrm{~min}$. Thereafter, the mixture was centrifuged at $200 \mathrm{~g}$ for $5 \mathrm{~min}$ and the cells were re-suspended with $200 \mu \mathrm{L}$ PBS containing $0.5 \%$ BSA (w/v) for flow cytometry analysis. The transfection efficiency is evaluated based on flow cytometry to count the total number of GFP cells. The cell viability is evaluated based on flow cytometry counting of total dead cells. A total of 5000 events were measured in each sample at a flow rate of approximately 80 events/s. 


\section{Results and Discussions}

\section{D-printing enabled micro-assembling of 3D $\mu$-electrotransfection system.}

To build a 3D microfluidic electro-transfection system that capable of uniform 3D electric field distribution as well as the effective 3D cell culture, we conceived an electroporation chip as shown in Fig. 1. Conventional microfabrication approach is unable to construct such 3D microstructures, due to complicated protocols for accurate alignment and multilayer bonding. Even though, it is very challenging for direct 3D printing of monolithic 3D microstructures, particularly micro-scale hollow channels. ${ }^{30-31}$ Therefore, we introduced the 3D-printing assisted molding of PDMS as the $\mathrm{LEGO}^{\circledR}$ blocks for assembling into a more complicated 3D device. As illustrated in Fig. 1a, two designed parts were assembled as one transfer mold for PDMS molding. The assembled mold is detachable for easily releasing PDMS parts. The PDMS polymer was completely cured in the mold and no microstructural defects were identified during the demolding process (Fig. 1d). Worth to mention that the high-temperature baking (e.g. $>40{ }^{\circ} \mathrm{C}$ ) should be avoided as the high temperature may cause physical structural distortion of $3 \mathrm{D}$ printed resin. The molded PDMS polymer replicates microstructures as a single assembling unit shown in Fig. 1c and d. After four units assembling with permanent bonding using surface plasma treatment, the 3D microfluidic electrotransfection device can be formed with four main vertical microchannels $(\sim 350 \mu \mathrm{m})$ each connected with five horizontal microchannels $(\sim 200 \mu \mathrm{m})$ (Fig. 1a). To facilitate the precise production of microstructures, sputtering $\mathrm{Ba}$ or Au coating was deposited onto the mold surface in 20-nm thick as shown in Fig. $1 \mathrm{~b}$ and c. The final assembled device can be bound onto a glass slide after surface plasma treatment. The electrodes were fixed in a 3D printed holder (Fig. 1e), which fits the central culture chamber for electroporating 3D cultured cells (Fig. 1f and Fig. 2a).

\section{Working principles of multi-directional electric field scanning enabled 3D transfection.}

In an electric filed across cells, the cell membrane is an electric insulator that separates extracellular medium with the intracellular medium. The ion concentration gradient between outside and inside of the cellular membrane generates a resting potential difference, which is homogenous all along the cell membrane. ${ }^{32}$ Upon application of voltage, such electric potential difference across the cellular membrane will disrupt the field lines, ${ }^{33,34}$ consequently, leading to the current forced to flow around the cell and forming the ionic layers along the cellular membrane. The largest field line distortion is recognized at the sides of the membrane facing the field lines. ${ }^{3,35}$ After reaching a certain intensity of field strength, the cell membrane can be disrupted to create transient pores. In a uniform electric field, the induced potential difference $(\Delta \Psi)$ at a point on the cell membrane and at a time after the rise of the electric pulse is given by ${ }^{3,36}$ :

$$
\Delta \Psi=f g(\lambda) \operatorname{Er} \cos (\theta)\left(1-e^{-t / \tau} c\right)
$$

Where $\theta$ is the angle formed between the direction of the electric field and a normal point on the membrane. $f$ is a factor related to the shape of the cell which equals to 1.5 if the cell is spherical. $g(\gamma)$ is a factor related to the conductivity of the membrane. $r$ is the semi-axis 
aligned along the electric field and $\tau_{c}$ is the charging time of the cell membrane. Because the membrane conductivity is extremely low compared to the conductivity of the intra and extracellular medium, it can be assumed that $g(\lambda)=1$. As the electric field pulse durations $\left(\tau_{\mathcal{C}}\right)$ is very small, at a steady state, considering the cell as a spherical insulator shell, $\Delta \Psi$ can be written in a simplified expression:

$$
\Delta \Psi=1.5 \operatorname{Er} \cos (\theta)
$$

Therefore, the induced potential difference on the cell membrane is directly proportional to the cell size and the strength of the electric field. Furthermore, the resting potential difference across the cell membrane reaches its maximum value at the side of the membrane facing the electric field directly $\left(0^{\circ}\right.$ or $\left.180^{\circ}\right)$, while decreases progressively along the cell surface up to the poles. Therefore, to open more pores on the cell membrane with mild voltage conditions, changing electric field directions to create pores from multiple sites on the cell membrane is more effective for electroporation. Therefore, in our experiments, the multi-directional electric frequency scanning method was developed, which can easily create transient pores all over the cell membrane along with the multi-directional scanning as demonstrated in Fig. 2b, as well as create local oscillation for enhancing mass transport and improving cell transfection efficiency. By COMSOL simulation in Fig $2 b$, the uniform electric field strength across the cell chamber is estimated at $1000 \mathrm{~V} / \mathrm{cm}$ with a voltage of $500 \mathrm{~V}$, which is sufficient to create transient pores on the cell membrane. In general, the electric field across cell clusters needs to reach the electroporation threshold ( 100 to 1000 $\mathrm{V} / \mathrm{cm}$, depending on cell type) allowing membrane disruption. ${ }^{3}$

To prove the effectiveness of multi-directional electric field induced membrane permeabilization for delivering targets into the cytoplasm, a small molecule dye PI was electro-delivered in the 3D cell system. PI is impermeable by the living cells with intact cell membrane, but can enter into cytoplasm under electric field induced membrane permeabilization. Comparing to other dyes with simultaneous permeation into living cells, the electro-delivery of PI can directly reflect the electric field induced membrane disruption and reseal process (electro-transfection). Note that our transfection voltage is $400 \mathrm{~V}$ (field strength is $\sim 800 \mathrm{~V} / \mathrm{cm}$ ) with four electric pulses $(16 \mathrm{~ms})$ at the frequency of $1 \mathrm{~Hz}$, which is kept the same for all the tests shown in Fig. 2d to $g$ and Fig s1, but manipulated from different directions (illustrated in Fig. $2 \mathrm{~d}$ to $\mathrm{g}$ insets). This electric field condition is below literature reported, well-recognized electroporation field strength $(\sim 2000 \mathrm{~V} / \mathrm{cm}$ for $>80 \%$ cell viability) for HeLa cells ${ }^{37-39}$. Meanwhile, our experimental study showed that our voltage condition at $400 \mathrm{~V}$ can achieve more than $90 \%$ cell viability (Fig. 5a). Thus, we ascertain that the red staining of cells is due to the electro-transfection process, not the dead cells. The further illustration was shown in Fig. s1. For clear visualization and evaluation of the amount of PI-delivered cells by our in-house inverted fluorescence microscope, we took the cells out of the hydrogel and dissociated cell clusters onto a glass slide for cytospin and imaging. The fluorescence of cytospin cells on the glass slide was tracked by the microscopy analysis to evaluate PI delivery efficiency. The single direction of the electric field only showed $\sim 40 \%$ cells transfected, which is much less than four directional scannings with over $80 \%$ cells transfected. Note that the total pulse duration for each test ( $\mathrm{d}$ to g) was the 
same, so the adverse effects caused by the electric field (heating, electrolysis, etc) were comparable. The multi-directional scanning can cover all over the cell membrane for creating more transient pores. Additionally, compared to using one electric field direction with long pulse duration, the short-duration pulsed scanning could reduce the risk on inducing irreversible electroporation, in turn, improving the cell viability. ${ }^{40-41}$

\section{D $\mu$-electrotransfection system for 3D cell culture.}

Unlike the 3D cell culture in the well plate where the medium exchange only takes place from the top of well plates, our system allows multi-directional diffusion of the fresh medium from both the top of cell matrix and the side of microchannel arrays surrounded the culture chamber in vertical and horizontal directions. In this culture system, diffusion is dominant and follows the Fick's law. Assuming the diffusion coefficient is the same for three different configurations, the time of diffusion to reach the steady status is determined by the distance of the concentration gradient. The shorter travel distance leads to a shorter time, in turn, help with the better nutrient supply. Such 3D perfusion microchannel network allows better nutrients support and waste exchange needed for the effective growth of 3D cells and tissues. Such diffusion-based perfusion has been well studied in 3D culture system to include multiple perfusion channels, which is consistent with our design theory ${ }^{42-43}$. The growth rate was illustrated and calibrated in Fig. s2. The cultured 3D cellular morphology was shown in Fig. s3 with a typical spheroid size of $100 \mu \mathrm{m}$ ( >10 cells). The mass transport and efficient diffusion of nutrients from multi-directions were proved by COMSOL simulation in Fig. 3, which indicates that 3D perfusion microchannel network significantly improves the medium exchange compared to the conventional 3D cell culture in the well plate.

We chose the peptide hydrogel as the scaffold for 3D cell growth in our 3D $\mu$ electrotransfection system shown in Fig. 4a, due to its high encapsulation stability, cell attachability and biocompatibility. ${ }^{44-45}$ Upon crosslinking, the hydrogel forms a porous matrix with the pore size ranged from 200 to $400 \mathrm{~nm}$, which gives a stable physical support for $3 \mathrm{D}$ cell growth as imaged in Fig. 4 e and f. ${ }^{27}$ Due to the perfusion microchannels for nutrients and waste exchange in our device, the high cell seeding density from $1 \times 10^{5}$ to $5 \times 10^{5}$ cells $/ \mathrm{mL}$ can be achieved. The cell showed excellent attachability to peptide fibers (Fig. 4f). The dense spheroid distribution in peptide hydrogel matrix in 3D as well as the morphology of a single spheroid have been characterized by confocal microscopy shown in Fig. $4 \mathrm{~b}$ to d. The confocal images depicting the different depths and locations of 3D cultured spheroids were shown in supplemental material Fig. s4. The side views demonstrated that cells are distributed along with the height of the cell chamber. The individual 3D spheroid with the size of $\sim 50 \mu \mathrm{m}$ was observed after culturing for 4-5 days which composes of $\sim 10$ cells as shown in Fig. $4 \mathrm{c}$ and 4 d. Such morphology characterization indicates that our 3D $\mu$-electrotransfection system provides suitable microenvironment for growing 3D cells and tissues, which is enabled by the implementation of 3D perfusion microchannels. 


\section{D $\mu$-electrotransfection of 3D cultured cells.}

To assess the transfection efficiency and cell viability of our 3D $\mu$-electrotransfection system, a plasmid DNA (pAcGFP1-C1) encoding GFP was electroporated into 3D cultured HeLa cells. For conventional electrotransfection of $2 \mathrm{D}$ cell suspension, the critical electric field needs to reach a value in a range from 100 to $1000 \mathrm{~V} / \mathrm{cm}$ (depending on cell size and electric field property) to disrupt cell membrane and ensure the reversible electroporation. 3,46 In the case of spheroid cells, the low electric field $(\sim 500 \mathrm{~V} / \mathrm{cm})$ with long pulses $(\sim 20$ ms) has been reported which leads to the transfected GFP expression. ${ }^{19,47}$ In contrast to the study of cell suspensions or isolated cell spheroids, we intended to deliver plasmid directly to $3 \mathrm{D}$ cells embedded in the extracellular matrix to mimic electroporation of in vivo like tissue microenvironment. Thus, we optimized the key parameters that control the electroporation efficiency, including electric field strength, plasmid concentration, pulse duration, and duty cycles.

Experiments were carried out after the cells were seeded on the chip for 48 hours. Fig. 5h to e shows a typical image and flow cytometry analysis of 3D cultured cells after electrotransfection in our system. The confocal microscopic imaging in Fig. 5e-g displays a transfected 3D cell spheroid with a diameter around $60 \mu \mathrm{m}$. With a voltage of $300 \mathrm{~V}$ in multi-directional field scanning (equal to an electric field of $750 \mathrm{~V} / \mathrm{cm}$ ), $2.5 \%$ GFP expressed cells were identified from the total cell population with cell viability of $\sim 95 \%$ by flow cytometry analysis (Fig. 5). The transfection efficiency was increasing while increasing the applied voltage from $300 \mathrm{~V}$ to $600 \mathrm{~V}$. However, the cell viability was decreased from $96 \%$ to $\sim 84 \%$, due to more dead cells caused by the high voltage, which in turn decreases the transfection efficiency with a higher voltage of $600 \mathrm{~V}(1500 \mathrm{~V} / \mathrm{cm})$ (Fig. 5 a-d). Either increasing the pulse duration or adding more duty cycles can lead to an increase of transfection efficiency, but the dead cells were dramatically increased accordingly, due to the harsh electric interruption of cell membrane irreversibly. Applying 4 duty cycles lead to the $15.6 \%$ transfection efficiency but with $58.3 \%$ cell viability. To find the balance between the transfection efficiency and cell viability for the best transfection outcome, the optimized voltage is $500 \mathrm{~V}$ with $\sim 120 \mu \mathrm{g} / \mathrm{mL}$ plasmid concentration, which showed a more important role in the control of good cell viability compared to the electric duty cycle and pulse. Increasing the plasmid concentration will create more contact opportunities between cells and plasmids, reflecting an increasing number of transfected cells. We kept pulse duration of $3 \mathrm{~ms}, 3$ duty cycles and transfection voltage of $500 \mathrm{~V}$. Using the optimal plasmid concentration of $\sim 120 \mu \mathrm{g} / \mathrm{mL}$, we achieved $15.2 \%$ transfection efficiency with $87.1 \%$ cell viability, which is 3 -fold increase than currently reported benchtop 3D electro-transfection method $^{21}$ with better cell viability. However, continuously increasing plasmid DNA concentration did not result in higher transfection efficiency. This observation agrees to the previous report that there is a maximum plasmid concentration for gene delivery. ${ }^{48}$ Compared to 2D cell transfection, the optimal plasmid concentration for 3D cell electroporation is much higher ( $110 \mathrm{vs} 40 \mu \mathrm{g} / \mathrm{mL}) .{ }^{49}$ This is attributed to the porous peptide hydrogel matrix which limits the travel of plasmid to cells and requires more amount of plasmid to enhance contact opportunities with cells. In addition to the scaffold matrix effect, the 3D cell spheroid is much bigger than an individual cell and the plasmid needs to travel a long distance to reach the cells inside the cluster, which makes the gene delivery even 
difficult. Our method with the electric filed scanning strategy could improve mass transport to address this challenge.

The HeK 293 cells are the classic model cell line for studying electro-delivery of CRISPR/ Cas $9^{50-51}$. For proving the applicability of our system in 3D tissue engineering, we transfected the CRISPR/Cas9 gene with 3D cultured Hek-293 cells. The CRISPR/Cas9 editing has emerged as a rapid and powerful approach to make precise and targeted changes to the genome of living cells. ${ }^{52}$ Recent studies have successfully demonstrated gene transfer to organoids by various methods including lentivirus transfection, ${ }^{53}$ liposomal transfection ${ }^{54}$ and electroporation. ${ }^{55}$ The advantage of electroporation over other methods is free of chemicals in the culture system. The plasmid can be delivered upon preparation and does not require producing lentivirus or carriers, which significantly reduces labor and time. In this experiment, a 9.2 Kb PX458 vector was delivered to 3D cultured HeK-293 cells using our 3D $\mu$-electrotransfection system. The EGFP protein encoded by this CRISPR/Cas9 vector was traced to evaluate the CRISPR/Cas9 delivery. The high concentration of CRISPR/Cas9 plasmid $(200 \mu \mathrm{g} / \mathrm{mL})$ was applied according to the previously optimized conditions, and the mild voltage $(400 \mathrm{~V}))$ and 2 duty cycles were chosen. Fig. 6a shows the 3D distribution of transfected Hek cells within the cultured extracellular matrix $(1.5 \mathrm{~mm} \times 1 \mathrm{~mm} \times 0.5 \mathrm{~mm})$. This image is a Multi-Stack Montage of x-scan, y-scan and z-scan in the large scale. Thus, each GFP expressed 3D cell cluster is viewed as a green dot. The fluorescence confocal imaging was performed with the $3 \mathrm{D}$ gel matrix which introduced the background showing as the red, due to light diffraction from the dense mesh gel structure. Fig. 6b shows the successfully transfected cell spheroids with $\sim 25$ cells in a perfect round cluster. Fig. $6 \mathrm{c}$ shows a single transfected cell in the status of the division. The uniform green fluorescence distribution within either the spheroids cluster or the divided two daughter cells proves the effective electroporation across overall cell cytoplasm. We also performed the nucleus staining using DAPI as shown in Fig. 6f and g which clearly showed the multiple cells clustered together to form this sphere shape. The clearance of peptide hydrogel scaffold background is very critical in confocal imaging. We summarized the protocols developed in our lab in the supplemental information. We also used the confocal imaging analysis tool "spot annotation" to count the number of cell nuclei across the $\mathrm{Z}$ stack in the region of interest. We measured multiple spheroids, and the average cell number is $\sim 25$. We also measured the typical cluster size using confocal imaging analysis and the average spheroid size is about $\sim 75-100 \mu \mathrm{m}$ which is clustered by $\sim 25-50$ individual cells. We further tuned the parameters by varying electric field strength and pulse duration, however, the transfection efficiency is not significantly improved. It is speculated that the bigger size of the CRISPR gene may not freely transport within the porous scaffold or entering the cell transient pores. It is also likely that gene editing efficiency ${ }^{56-58}$ may not represent the transfection efficiency due to expression off-target. Note that in this experiments we used green fluorescence emitted from GFP expressed cells to evaluate this transfection process. We could use a selective medium to remove non-transfected cells for continuously culturing CRISPR gene edited 3D cells for achieving the regulation of tissue functions. 


\section{Conclusions}

In recent years, 3D printing has been drawing much attention from the research community, which can create complex structures with high quality for fast prototyping ${ }^{59-61}$, compared to the traditional micro-fabrication. As a layer-by-layer manufacturing method, 3D printing not only achieves monolithic device fabrication but also allows for printing molds in producing PDMS microfluidic chip. However, constructing complex 3D structures and monolithic hollow channels in micro-scale is still challenging. In this paper, we take advantages of 3D printing and $\mathrm{LEGO}^{\circledR}$ assembling concept for re-constructing more complicated 3D microfluidic channels, which extends the 3D printing capability for creating unattainable 3D micro-geometries and introducing geometrics enabled functionality. Such assembled 3D $\mu$ electrotransfection system allows spatial and temporal control of electric field uniformly in three dimensions. Therefore, the multi-directional electric frequency scanning is achievable for maximizing the electroporation efficiency via enhancing the resting potential difference across all over the cell membrane. Furthermore, this scanning process also creates local oscillation for enhancing mass transport and improving cell transfection efficiency. ${ }^{62}$ The 3D-cell culture performance is improved as well due to the enhanced medium perfusion via inter-connected vertical and horizontal perfusion microchannels array, which is reconstructed by this $3 \mathrm{D}$ printing-assisted molding and assembling process.

Existing microfluidic electroporation approaches are only able to study monolayer cell suspensions in vitro, which is incapable of clinical translation within in vivo tissue microenvironment, but essential in gene therapy and tissue repair. Up to now, the study of electroporation on 3D cultured cells within the extracellular matrix has not been well explored. Thus, our work could build an effective 3D-cell electroporation model to bridge such a gap. Our work introduced the first 3D microfluidic electroporation system for transfecting 3D cultured cells, which demonstrated $\sim 3$-fold increase of transfection efficiency with good cell viability (> 85\%), compared to the conventional benchtop 3D-cell electro-transfection. ${ }^{21}$ The optimization of several key parameters, including electric field strength, plasmid concentration, pulse duration and duty cycles, gave a good rationale for understanding the influence on the delivery process and cell viability. The threshold of permeabilization voltage and plasmid concentration play more important roles, due to the direct connection with the chances of transient pore opening and contact. Due to the limited mass transport of cargos through the porous cellular matrix to cells, the 3D transfection is more challenging. The hard-to-transfect cells generally have lower transfection efficiency. Our approach with the multi-dimensional frequency scanning enhanced the transfection efficiency, compared to current existing 3D electroporation methods. ${ }^{21}$ Compared with other transfection approaches, such as the chemical transfection of scaffold embedded 3D cells which requires more than 24 hours incubation, our approach is much simple and fast (less than 1 hour).

The HeLa and HeK 293 cells are the classic model cell lines for studying electroporation, due to their biological stability during the culture growth. Thus, the study could serve as a good cross reference for demonstrating the performance of our device in terms of 3D culture and 3D electroporation. The voltage threshold for cellular electroporation and opening transient pores is cell-type dependent. ${ }^{3}$ Generally, no matter what type of transfection 
approaches, 3D spheroids that are comprised of 3D cells are more difficult to transfect compared to floating individual cells, due to the irregular and dense 3D cellular morphology, as well as the complicated scaffold materials. Our 3D culture method grows single individual cells into 3D spheroids in the scaffold, which mimics the in vivo cellular interactions with ECM. The typical size of spheroids is around $\sim 50-150 \mu \mathrm{m}(\sim 10$ cells per spheroid), which is consistent with other reported 3D culture methods. ${ }^{27,63-65}$

This study also can mimic the intracellular delivery of therapeutic molecules in vivo and has important implications for gene delivery in tissues, especially for editing cells in vivo using CRISPR/Cas9 method. The future work will be conducted to further enhance transfection efficiency by investigating different scaffolds with various conductivity and porosity. This $3 \mathrm{D}$ re-constructed $\mu$-electrotransfection platform can serve as a good model system for studying and mimicking in vivo electro-transfection process, and building the foundation for developing more effective clinical gene delivery approaches.

\section{Supplementary Material}

Refer to Web version on PubMed Central for supplementary material.

\section{Acknowledgments}

We acknowledge the funding support from USDA-NIFA KS451214 and NIH P20 NIH0078730, as well as the KINBRE Postdoctoral Scholarship (P20 GM103418) for QZ. We also thank the assistant from the Confocal Core at the University of Kansas and the Kansas State University for imaging 3D cells.

\section{References}

1. Stewart MP; Sharei A; Ding X; Sahay G; Langer R; Jensen KF, In vitro and ex vivo strategies for intracellular delivery. Nature 2016, 538, 183. [PubMed: 27734871]

2. Evans CH; Huard J, Gene therapy approaches to regenerating the musculoskeletal system. Nature Reviews Rheumatology 2015, 11, 234. [PubMed: 25776949]

3. Christelle R; Haberl Sasa M.; Andreas Z; Marie-Pierre R; Damijan M, Gene Electrotransfer: A Mechanistic Perspective. Current Gene Therapy 2016, 16 (2), 98-129. [PubMed: 27029943]

4. A., I. J.; G., C.; L., A., Electro-gene-transfer as a new tool for cancer immunotherapy in animals. Veterinary and Comparative Oncology 2014, 12 (4), 310-318. [PubMed: 23095099]

5. Broderick KE; Humeau LM, Electroporation-enhanced delivery of nucleic acid vaccines. Expert Review of Vaccines 2015, 14 (2), 195-204. [PubMed: 25487734]

6. Bhattacharjee N; Horowitz LF; Folch A, Continuous-flow multi-pulse electroporation at low DC voltages by microfluidic flipping of the voltage space topology. Appl Phys Lett 2016, 109 (16), 163702.

7. Garcia PA; Ge Z; Moran JL; Buie CR, Microfluidic Screening of Electric Fields for Electroporation. Sci Rep 2016, 6, 21238. [PubMed: 26893024]

8. Bian S; Zhou Y; Hu Y; Cheng J; Chen X; Xu Y; Liu P, High-throughput in situ cell electroporation microsystem for parallel delivery of single guide RNAs into mammalian cells. Sci Rep 2017, 7, 42512. [PubMed: 28211892]

9. Geng T; Lu C, Microfluidic electroporation for cellular analysis and delivery. Lab Chip 2013, 13 (19), 3803-21. [PubMed: 23917998]

10. Yun H; Hur SC, Sequential multi-molecule delivery using vortex-assisted electroporation. Lab Chip 2013, 13 (14), 2764-72. [PubMed: 23727978]

11. Chang L; Li L; Shi J; Sheng Y; Lu W; Gallego-Perez D; Lee LJ, Micro-/nanoscale electroporation. Lab Chip 2016, 16 (21), 4047-4062. [PubMed: 27713986] 
12. Fox MB; Esveld DC; Valero A; Luttge R; Mastwijk HC; Bartels PV; van den Berg A; Boom RM, Electroporation of cells in microfluidic devices: a review. Anal Bioanal Chem 2006, 385 (3), 474 85. [PubMed: 16534574]

13. Lu H; Schmidt MA; Jensen KF, A microfluidic electroporation device for cell lysis. Lab Chip 2005, 5 (1), 23-9. [PubMed: 15616736]

14. Ravi M; Paramesh V; Kaviya SR; Anuradha E; Solomon FD, 3D cell culture systems: advantages and applications. J Cell Physiol 2015, 230 (1), 16-26. [PubMed: 24912145]

15. Justice BA; Badr NA; Felder RA, 3D cell culture opens new dimensions in cell-based assays. Drug Discovery Today 2009, 14 (1), 102-107. [PubMed: 19049902]

16. Kandušer M; Miklavčič D, Electroporation in Biological Cell and Tissue: An Overview In Electrotechnologies for Extraction from Food Plants and Biomaterials, Springer New York: New York, NY, 2008; pp 1-37.

17. Stewart MP; Langer R; Jensen KF, Intracellular Delivery by Membrane Disruption: Mechanisms, Strategies, and Concepts. Chem Rev 2018, 118 (16), 7409-7531. [PubMed: 30052023]

18. Zhang Y; Satterlee A; Huang L, In vivo gene delivery by nonviral vectors: overcoming hurdles? Mol Ther 2012, 20 (7), 1298-304. [PubMed: 22525514]

19. Wasungu L; Escoffre JM; Valette A; Teissie J; Rols MP, A 3D in vitro spheroid model as a way to study the mechanisms of electroporation. Int J Pharmaceut 2009, 379 (2), 278-284.

20. Gibot L; Rols MP, 3D spheroids' sensitivity to electric field pulses depends on their size. J Membr Biol 2013, 246 (10), 745-50. [PubMed: 23519620]

21. Haberl S; Pavlin M, Use of collagen gel as a three-dimensional in vitro model to study electropermeabilization and gene electrotransfer. J Membr Biol 2010, 236 (1), 87-95. [PubMed: 20640849]

22. Gibot L; Rols M-P, 3D Spheroids' Sensitivity to Electric Field Pulses Depends on Their Size. The Journal of Membrane Biology 2013, 246 (10), 745-750. [PubMed: 23519620]

23. Sapet C; Formosa C; Sicard F; Bertosio E; Zelphati O; Laurent N, 3D-fection: cell transfection within 3D scaffolds and hydrogels. Therapeutic Delivery 2013, 4 (6), 673-685. [PubMed: 23738666]

24. Morgan RG; Chambers AC; Legge DN; Coles SJ; Greenhough A; Williams AC, Optimized delivery of siRNA into 3D tumor spheroid cultures in situ. Scientific Reports 2018, 8 (1), 7952. [PubMed: 29785035]

25. Plevniak K; Campbell M; Myers T; Hodges A; He M, 3D printed auto-mixing chip enables rapid smartphone diagnosis of anemia. Biomicrofluidics 2016, 10 (5), 054113.

26. Zhu Q; Zhu Z; He M, 3D Additive Manufacturing and Micro-Assembly for Transfection of 3DCultured Cells and Tissues. Conference: ASME 2018 13th International Manufacturing Science and Engineering Conference 2018.

27. Huang H; Ding Y; Sun XS; Nguyen TA, Peptide Hydrogelation and Cell Encapsulation for 3D Culture of MCF-7 Breast Cancer Cells. PLOS ONE 2013, 8 (3), e59482.

28. Geng T; Zhan Y; Wang J; Lu C, Transfection of cells using flow-through electroporation based on constant voltage. Nat Protoc 2011, 6 (8), 1192-208. [PubMed: 21799488]

29. Ashwanikumar N; Kumar NA; Babu Saneesh P. S.; Sivakumar KC; Vadakkan MV; Nair P; Hema Saranya I; Nair Asha S.; Kumar Vinod G. S., Self-assembling peptide nanofibers containing phenylalanine for the controlled release of 5-fluorouracil. Int J Nanomedicine 2016, 11, 55835594. [PubMed: 27822037]

30. Waheed S; Cabot JM; Macdonald NP; Lewis T; Guijt RM; Paull B; Breadmore MC, 3D printed microfluidic devices: enablers and barriers. Lab Chip 2016, 16 (11), 1993-2013. [PubMed: 27146365]

31. Sochol RD; Sweet E; Glick CC; Wu S-Y; Yang C; Restaino M; Lin L, 3D printed microfluidics and microelectronics. Microelectronic Engineering 2018, 189, 52-68.

32. Gaynor PT; Bodger PS, Physical modelling of electroporation in close cell-to-cell proximity environments. Phys Med Biol 2006, 51 (12), 3175-88. [PubMed: 16757870]

33. André F; Mir LM, DNA electrotransfer: its principles and an updated review of its therapeutic applications. Gene Therapy 2004, 11, S33. [PubMed: 15454955] 
34. Zimmermann U, Electric field-mediated fusion and related electrical phenomena. Biochimica et Biophysica Acta (BBA) - Reviews on Biomembranes 1982, 694 (3), 227-277. [PubMed: 6758848]

35. Krassowska W; Filev PD, Modeling Electroporation in a Single Cell. Biophysical Journal 2007, 92 (2), 404-417. [PubMed: 17056739]

36. Teissie J; Rols MP, An Experimental Evaluation of the Critical Potential Difference Inducing CellMembrane Electropermeabilization. Biophysical Journal 1993, 65 (1), 409-413. [PubMed: 8369446]

37. Chicaybam L; Barcelos C; Peixoto B; Carneiro M; Limia CG; Redondo P; Lira C; ParaguassuBraga F; Vasconcelos ZF; Barros L; Bonamino MH, An Efficient Electroporation Protocol for the Genetic Modification of Mammalian Cells. Front Bioeng Biotechnol 2016, 4, 99. [PubMed: 28168187]

38. Hornstein BD; Roman D; Arevalo-Soliz LM; Engevik MA; Zechiedrich L, Effects of Circular DNA Length on Transfection Efficiency by Electroporation into HeLa Cells. PLoS One 2016, 11 (12), e0167537.

39. Glahder J; Norrild B; Persson MB; Persson BR, Transfection of HeLa-cells with pEGFP plasmid by impedance power-assisted electroporation. Biotechnol Bioeng 2005, 92 (3), 267-76. [PubMed: 16161165]

40. Sun C; Cao Z; Wu M; Lu C, Intracellular Tracking of Single Native Molecules with Electroporation-Delivered Quantum Dots. Anal Chem 2014, 86 (22), 11403-11409. [PubMed: 25341054]

41. Zhan Y; Cao Z; Bao N; Li J; Wang J; Geng T; Lin H; Lu C, Low-frequency ac electroporation shows strong frequency dependence and yields comparable transfection results to dc electroporation. Journal of Controlled Release 2012, 160 (3), 570-576. [PubMed: 22516092]

42. Piola M; Soncini M; Cantini M; Sadr N; Ferrario G; Fiore GB, Design and functional testing of a multichamber perfusion platform for three-dimensional scaffolds. ScientificWorldJournal 2013, 2013, 123974.

43. Rouwkema J; Koopman B; Blitterswijk C; Dhert W; Malda J, Supply of nutrients to cells in engineered tissues. Biotechnol Genet Eng Rev 2010, 26, 163-78. [PubMed: 21415880]

44. Zhiqiang Y; Quan X; Chenbo D; Seong Su L.; Liqian G; Yiwen L; Mathew D; Ortenzio; Jun W, Self-Assembling Peptide Nanofibrous Hydrogel as a Versatile Drug Delivery Platform. Current Pharmaceutical Design 2015, 21 (29), 4342-4354. [PubMed: 26323419]

45. Jonker AM; Löwik DWPM; van Hest JCM, Peptide- and Protein-Based Hydrogels. Chemistry of Materials 2012, 24 (5), 759-773.

46. Garcia PA; Ge Z; Moran JL; Buie CR, Microfluidic Screening of Electric Fields for Electroporation. Scientific Reports 2016, 6, 21238. [PubMed: 26893024]

47. Marrero B; Heller R, The use of an in vitro 3D melanoma model to predict in vivo plasmid transfection using electroporation. Biomaterials 2012, 33 (10), 3036-3046. [PubMed: 22244695]

48. Potter H; Heller R, Transfection by Electroporation. Current protocols in molecular biology / edited by Ausubel Frederick M....[et al.] 2003, CHAPTER, Unit-9.3.

49. Tatsufumi M; Yoshihide S, Plasmid DNA Gene Therapy by Electroporation: Principles and Recent Advances. Current Gene Therapy 2011, 11 (6), 447-456. [PubMed: 22023474]

50. Lino CA; Harper JC; Carney JP; Timlin JA, Delivering CRISPR: a review of the challenges and approaches. Drug Deliv 2018, 25 (1), 1234-1257. [PubMed: 29801422]

51. Li Z; Zhao J; Muhammad N; Wang D; Mao Q; Xia H, Establishment of a HEK293 cell line by CRISPR/Cas9-mediated luciferase knock-in to study transcriptional regulation of the human SREBP1 gene. Biotechnol Lett 2018, 40 (11-12), 1495-1506. [PubMed: 30232659]

52. Ran FA; Hsu PD; Wright J; Agarwala V; Scott DA; Zhang F, Genome engineering using the CRISPR-Cas9 system. Nat Protoc 2013, 8 (11), 2281-2308. [PubMed: 24157548]

53. Koo B-K; Stange DE; Sato T; Karthaus W; Farin HF; Huch M; van Es JH; Clevers H, Controlled gene expression in primary Lgr5 organoid cultures. Nature Methods 2011, 9, 81. [PubMed: 22138822]

54. Schwank G; Koo B-K; Sasselli V; Dekkers Johanna F.; Heo I; Demircan T Sasaki N; Boymans S; Cuppen E; van der Ent Cornelis K.; Nieuwenhuis Edward E. S.; Beekman Jeffrey M.; Clevers H, 
Functional Repair of CFTR by CRISPR/Cas9 in Intestinal Stem Cell Organoids of Cystic Fibrosis Patients. Cell Stem Cell 2013, 13 (6), 653-658. [PubMed: 24315439]

55. Fujii M; Matano M; Nanki K; Sato T, Efficient genetic engineering of human intestinal organoids using electroporation. Nature Protocols 2015, 10, 1474. [PubMed: 26334867]

56. Wang X; Lu J; Lao K; Wang S; Mo X; Xu X; Chen X; Mo B, Increasing the efficiency of CRISPR/ Cas9-based gene editing by suppressing RNAi in plants. Sci China Life Sci 2019.

57. Mao Y; Yang X; Zhou Y; Zhang Z; Botella JR; Zhu JK, Manipulating plant RNA-silencing pathways to improve the gene editing efficiency of CRISPR/Cas9 systems. Genome Biol 2018, 19 (1), 149. [PubMed: 30266091]

58. Chu VT; Weber T; Wefers B; Wurst W; Sander S; Rajewsky K; Kuhn R, Increasing the efficiency of homology-directed repair for CRISPR-Cas9-induced precise gene editing in mammalian cells. Nat Biotechnol 2015, 33 (5), 543-8. [PubMed: 25803306]

59. Bhattacharjee N; Urrios A; Kang S; Folch A, The upcoming 3D-printing revolution in microfluidics. Lab Chip 2016, 16 (10), 1720-1742. [PubMed: 27101171]

60. Waheed S; Cabot JM; Macdonald NP; Lewis T; Guijt RM; Paull B; Breadmore MC, 3D printed microfluidic devices: enablers and barriers. Lab Chip 2016, 16 (11), 1993-2013. [PubMed: 27146365]

61. Yong H; Yan W; Jian-zhong F; Qing G; Jing-jiang Q, Developments of 3D Printing Microfluidics and Applications in Chemistry and Biology: a Review. Electroanalysis 2016, 28 (8), 1658-1678.

62. Rebersek M; Faurie C; Kanduser M; Corovic S; Teissie J; Rols MP; Miklavcic D, Electroporator with automatic change of electric field direction improves gene electrotransfer in-vitro. Biomed Eng Online 2007, 6, 25. [PubMed: 17601347]

63. Lee GY; Kenny PA; Lee EH; Bissell MJ, Three-dimensional culture models of normal and malignant breast epithelial cells. Nature Methods 2007, 4, 359. [PubMed: 17396127]

64. Wolun-Cholewa M; Langer K; Szymanowski K; Glodek A; Jankowska A; Warchol W; Langer J, An Efficient 3D Cell Culture Method on Biomimetic Nanostructured Grids. PLOS ONE 2013, 8 (9), e72936.

65. Tibbitt MW; Anseth KS, Hydrogels as extracellular matrix mimics for 3D cell culture.

Biotechnology and Bioengineering 2009, 103 (4), 655-663. [PubMed: 19472329] 


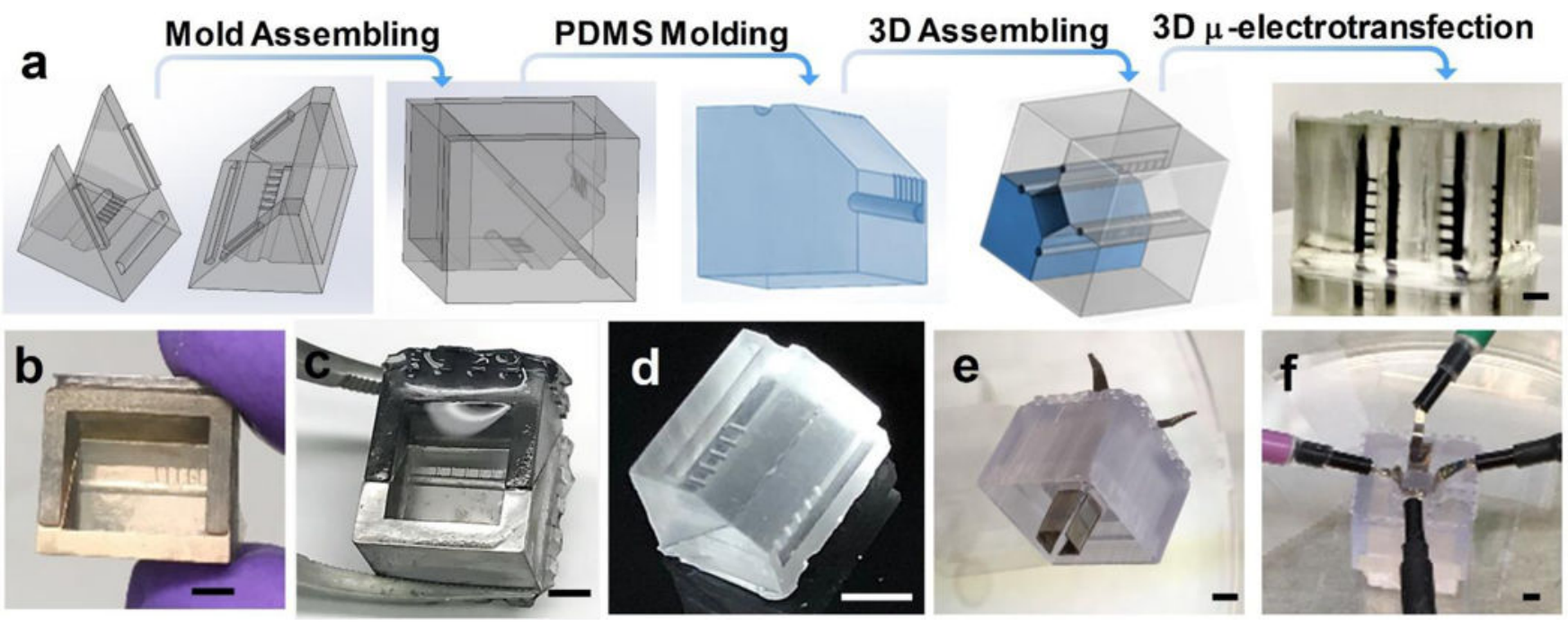

Fig. 1.

3D printing assisted $\mathrm{LEGO}{ }^{\circledR}$ assembling for building $3 \mathrm{D} \mu$-electroporation system. a) The concept illustration of 3D printing, molding and LEGO ${ }^{\circledR}$ assembling. The last image shows the real four-piece assembled device bound to a glass slide with channels filled in black dye. The scale bar is $1 \mathrm{~mm}$. b) 3D printed mold ( 2 pieces assembled) with the surface deposited by $20-\mathrm{nm} \mathrm{Au}$. The scale bar is $2 \mathrm{~mm}$. c) The mold (with 20-nm Ba coating) filled with PDMS and the molded PDMS part is shown in figure d. The scale bar is $2 \mathrm{~mm}$. e) Four electrodes mounted in a 3D printed holder. The scale bar is $2 \mathrm{~mm}$. f) The setup of four electrodes on top of cell culture chip for multi-dimensional electric frequency scanning. The electrodes are just fitting to the size of the culture chamber. The scale bar is $2 \mathrm{~mm}$. 

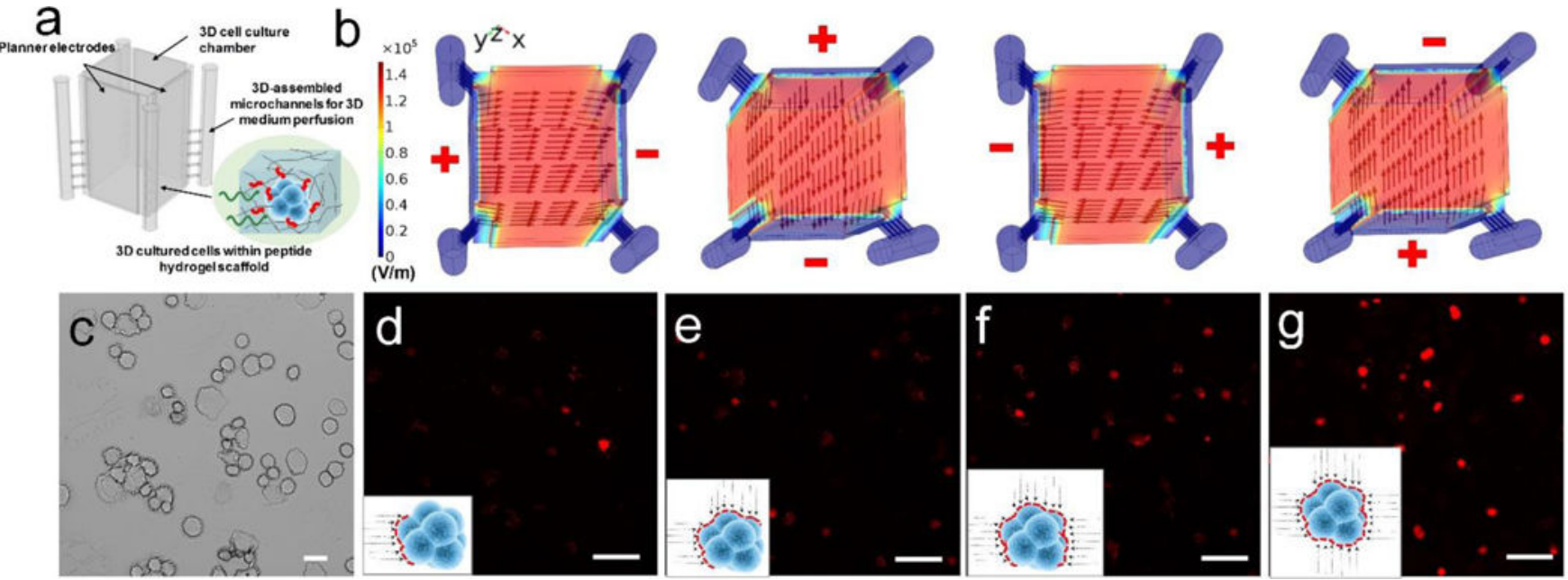

Fig. 2.

a) Illustration of on-chip 3D cell culture. b) COMSOL simulation of electric field distribution across the cell culture chamber with the multi-directional field scanning strategy. A voltage of $400 \mathrm{~V}$ was applied. Arrows indicate the intensity and direction of the electric field. c) Control sample without applying an electric field under a bright field. The scale bar is $20 \mu \mathrm{m}$. d) one-direction electric filed based PI delivery. e) two-direction electric filed based PI delivery. f) Three-direction electric filed based PI delivery. g) Four-direction electric filed based PI delivery. The scale bar is $50 \mu \mathrm{m}$ for Fig. $2 \mathrm{~d}$ to $\mathrm{g}$. 

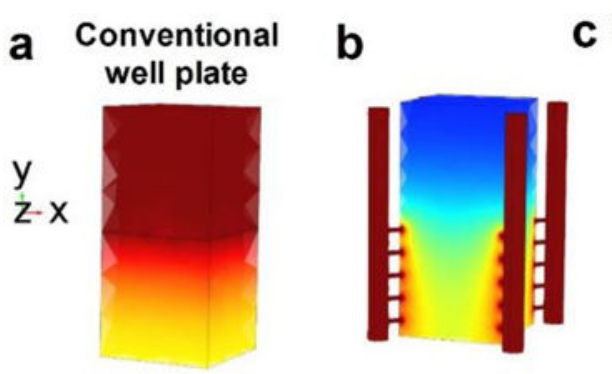

C 3D $\mu$-electrotransfection
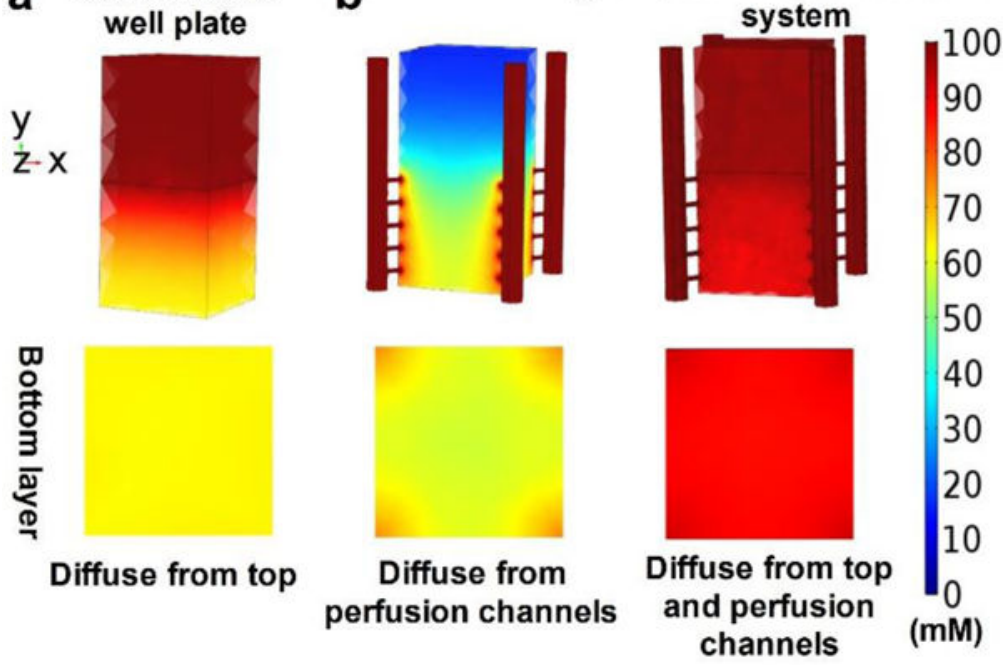

Fig. 3.

COMSOL simulations of medium diffusion. a) Diffusion from top medium to cell matrix in the vertical direction for the conventional well plate. b) Diffusion from microchannel network to cell matrix in the horizontal directions. c) Diffusion from both the microchannel network and top medium. $100 \mathrm{mM}$ ionic strength was used in the fresh medium for simulation. 

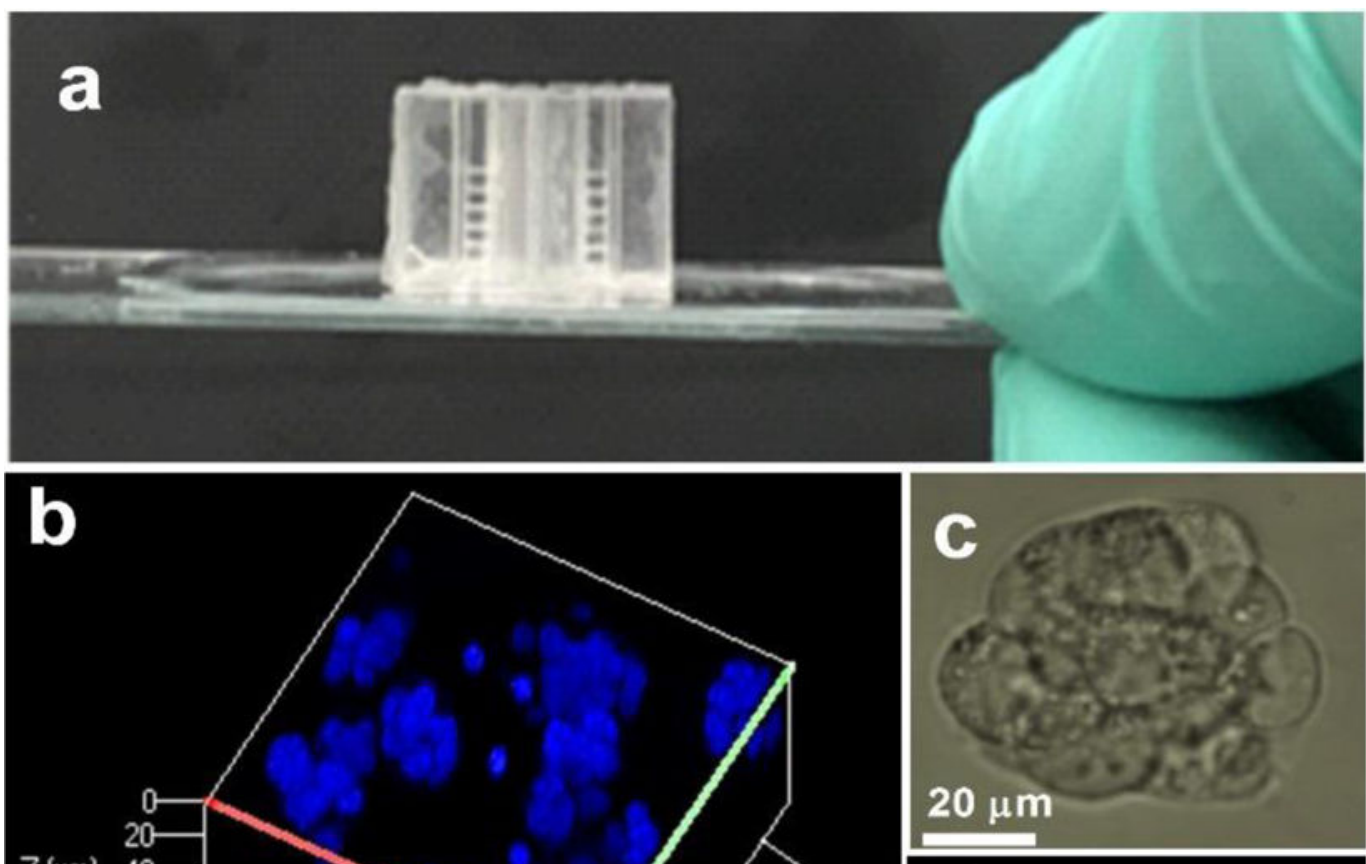

$Z$ ( $\mu \mathrm{m})$
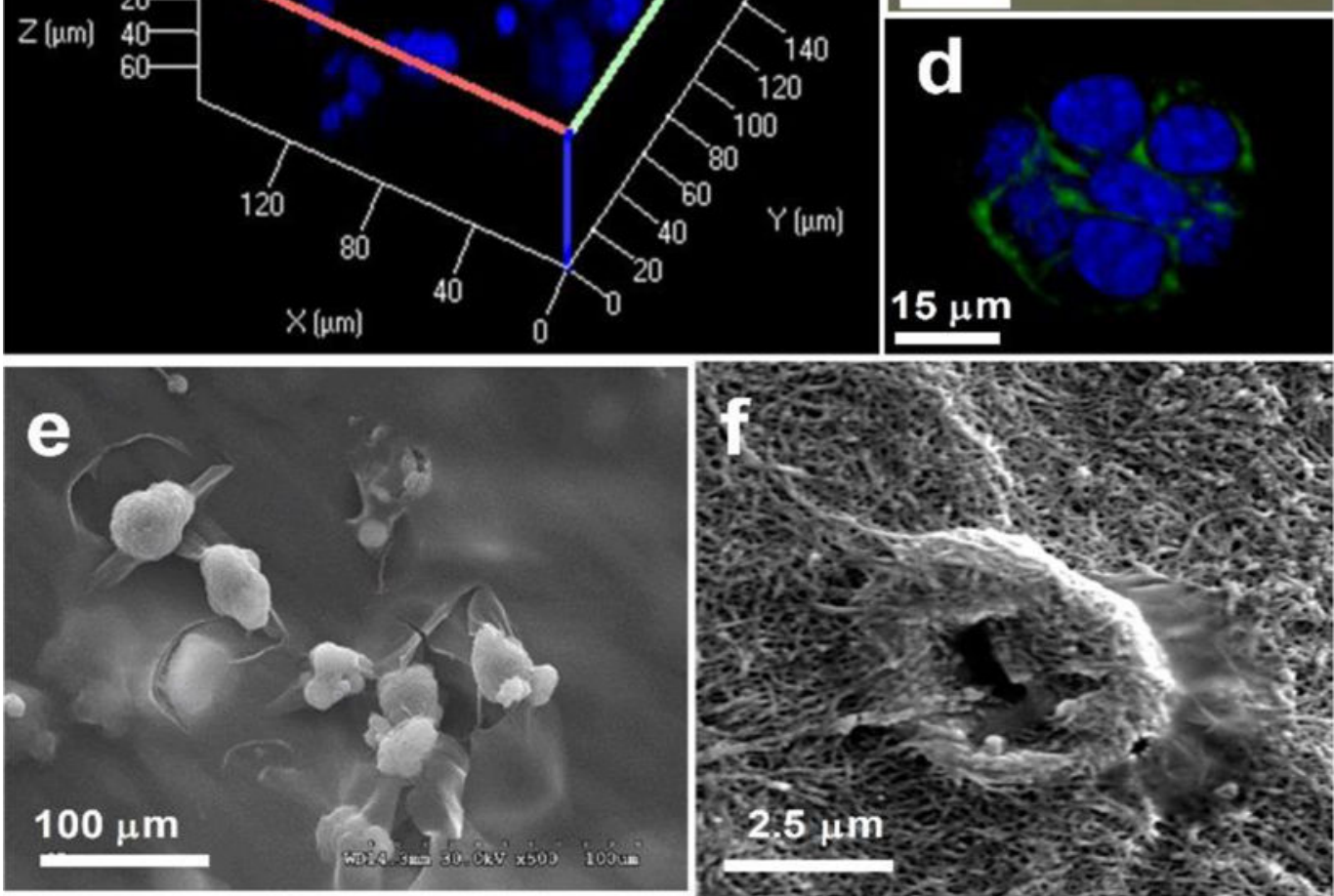

Fig. 4.

On-chip 3D cell culture and microscopy characterization. a) Assembled PDMS chip bound to a glass slide for cell culture. b) Distribution of 3D-cultured HeLa cell spheroids in peptide hydrogel under confocal microscope imaging. Nuclear DNA was stained by Hoechst. c) The close look of a single 3D cell spheroid in bright field and in the fluorescence channels in $\mathrm{d}$. The cell membrane was stained by FITC conjugated antibody-dye and the nuclear DNA was stained by Hoechst. e) SEM imaging the cell spheroid distribution and the single spheroid interacting with peptide fibers in $\mathrm{f}$. 

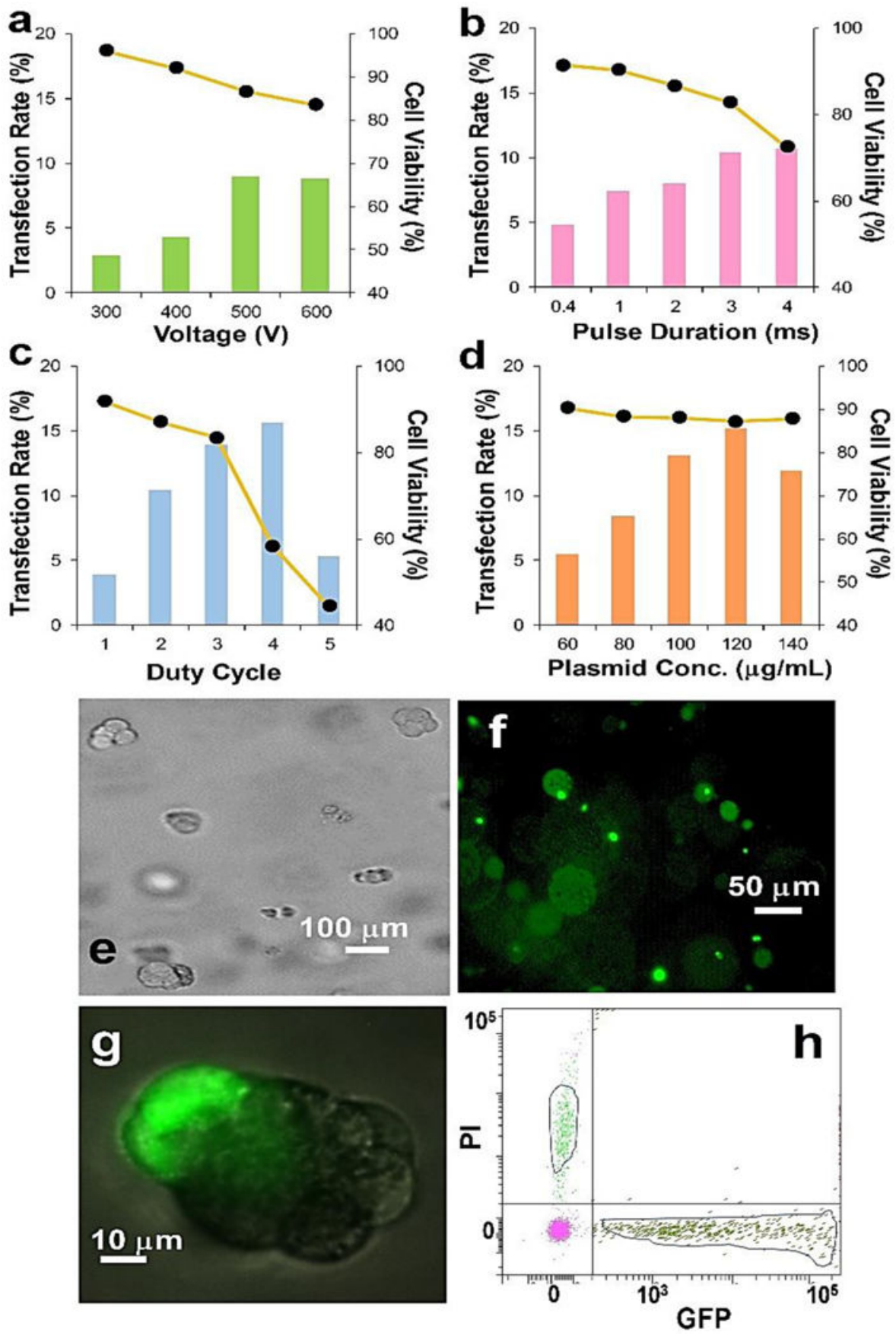

Fig. 5.

Electro delivery of GFP plasmid to 3D cultured HeLa cell spheroid within peptide hydrogel. a) Investigation of the influence of transfection voltage on the transfection rate and cell viability. The plasmid concentration is $100 \mu \mathrm{g} / \mathrm{mL}$, the pulse duration is $2 \mathrm{~ms}$, and the duty cycle is 2 . b) Investigation of the influence of pulse duration on the transfection rate and cell viability. The plasmid concentration is $100 \mu \mathrm{g} / \mathrm{mL}$, the duty cycle is 2 , and the transfection voltage is $500 \mathrm{~V}$. c) Investigation of the influence of duty cycle on the transfection rate and cell viability. The plasmid concentration is $100 \mu \mathrm{g} / \mathrm{mL}$, the pulse duration is $3 \mathrm{~ms}$, and the 
transfection voltage is $500 \mathrm{~V}$. d) Investigation of the influence of plasmid concentration on the transfection rate and cell viability. The pulse duration is $3 \mathrm{~ms}$, the duty cycle is 3 , and the transfection voltage is $500 \mathrm{~V}$. The yellow dot lines in Fig a-d indicate the cell viability. e) Electroporated sample under the bright field and FITC channel in $\mathrm{f}$. The transfection voltage was $500 \mathrm{~V}$ with a pulses duration of $3 \mathrm{~ms}$ for each direction, at the frequency of $1 \mathrm{~Hz}$, and 3 duty cycles. g) Confocal image of a transfected cell spheroid. h) Representative flow cytometry graph to evaluate the GFP positive cell and PI positive cell for estimating cell transfection efficiency and cell viability. The transfection voltage was $500 \mathrm{~V}$ with a pulses duration of $3 \mathrm{~ms}$ for each direction, at the frequency of $1 \mathrm{~Hz}$, and 3 duty cycles. The cell transfection efficiency is $13.5 \%$ with $85 \%$ cell viability. 

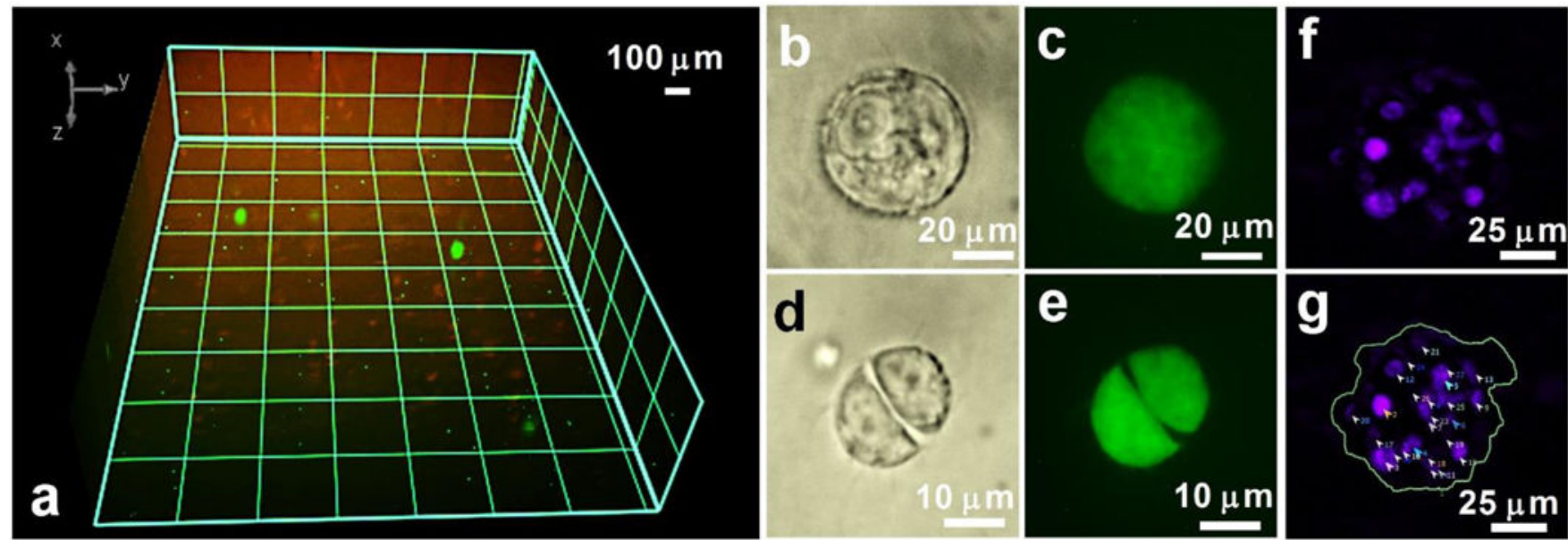

Fig. 6.

Electroporating the CRISPR/Cas9 plasmid (PX458) to 3D cultured Hek-293 cells. a) The overview of the transfected cells in the 3D matrix $(1.5 \mathrm{~mm} \times 1 \mathrm{~mm} \times 0.5 \mathrm{~mm})$. This image is from the stacking of $x$-scan, $y$-scan and z-scan (Multi Stack Montage) in large scale. Thus, each GFP expressed 3D cell cluster is viewed as a green dot. b) A transfected Hek-293 cell spheroid ( 25 cells) under the bright field and in FITC channel in c. d) A single transfected cell in the status of the division under the bright field and the FITC channel in e. f) Confocal image showing the DAPI stained cell nuclei which prove multiple individual cells to form the perfect 3D round shape of Hek spheroid. g) Confocal imaging analysis of the of cell nuclei across the $\mathrm{Z}$ stack using spot annotation to the region of interest. 